\title{
Repeated Autogenous Healing in Strain-Hardening Cementitious Composites by Using Superabsorbent Polymers
}

\author{
D. Snoeck, Ph.D. ${ }^{1}$; and N. De Belie, Ph.D. ${ }^{2}$
}

\begin{abstract}
Autogenous healing is an already-present feature in strain-hardening cementitious materials, but it is an inferior mechanism because it can only heal small cracks in the presence of water. A cementitious material with synthetic microfibers and superabsorbent polymers (SAPs) could provide a solution. In this study, the ability of repeatable promoted autogenous healing in fiber-reinforced, strain-hardening cementitious materials with and without SAPs is investigated by comparing their mechanical properties after they are subjected to two cycles of loading under a four-point-bending test. The results indicate that SAP particles promote self-healing. The main mechanisms of the autogenous healing are the hydration of unhydrated cementitious materials in cracks and the precipitation of calcium carbonate on the crack faces. The healed specimens are able to regain some of their mechanical properties (up to 75\%). Even second reloading of those healed samples leads to partial additional regain in mechanical properties (up to 66\%). DOI: 10.1061/(ASCE)MT.1943-5533 .0001360. (C) 2015 American Society of Civil Engineers.
\end{abstract}

Author keywords: Self-healing; Repeatability; Durability; Mortar; Hydrogels; $\mathrm{CaCO}_{3}$.

\section{Introduction}

Cracks can easily occur in concrete due to its relatively low tensile strength. These cracks have a negative effect on the durability of the structure because harmful substances may enter and deteriorate the concrete from inside out. This can be pernicious because repair works, which are labor-intensive and expensive, can sometimes not be effectuated due to inaccessibility or practical reasons. Concrete, however, has the ability to heal itself by closing small cracks, referred to as autogenous healing. The two mechanisms mainly responsible for this form of healing are (1) the continued hydration of unhydrated cement grains; and (2) the precipitation of calcium carbonate $\left(\mathrm{CaCO}_{3}\right)$ (Edvardsen 1999; Granger et al. 2007; Homma et al. 2009; ter Heide 2005; Van Tittelboom et al. 2012; Yang et al. 2009). In the last case, carbon dioxide $\left(\mathrm{CO}_{2}\right)$ dissolves in water to react with $\mathrm{Ca}^{2+}$ ions present in the mortar matrix. A detailed study on the autogenous healing of cracks in concrete and the boundary conditions needed was performed by Edvardsen (1999). She found a reduced permeability in time due to autogenous healing and performed an intensive study on the laws that govern the nucleation and crystal growth processes. The decrease in permeability hereby demonstrated the potential of the autogenous healing because there is less intrusion of durability-decreasing substances and thus a probability of an increased service life of the concrete structure.

\footnotetext{
${ }^{1}$ Magnel Laboratory for Concrete Research, Dept. of Structural Engineering, Faculty of Engineering and Architecture, Ghent Univ., Technologiepark Zwijnaarde 904, B-9052 Ghent, Belgium (corresponding author). E-mail: didier.snoeck@ugent.be

${ }^{2}$ Professor, Magnel Laboratory for Concrete Research, Dept. of Structural Engineering, Faculty of Engineering and Architecture, Ghent Univ., Technologiepark Zwijnaarde 904, B-9052 Ghent, Belgium. E-mail: nele .debelie@ugent.be

Note. This manuscript was submitted on September 22, 2014; approved on April 8, 2015; published online on June 11, 2015. Discussion period open until November 11, 2015; separate discussions must be submitted for individual papers. This paper is part of the Journal of Materials in Civil Engineering, (C) ASCE, ISSN 0899-1561/04015086(11)/\$25.00.
}

Cracks in high-strength cementitious materials need to be small in order to be completely healable. If not, the products available in the mortar mix are consumed before the crack is effectively closed. The wanted cracking behavior (the formation of multiple small cracks instead of a single large crack) is obtained by adding synthetic microfibers to the mortar mix, typically two volume-percent (2 v\%) of polyvinyl alcohol (PVA) fibers. This results in a mortar with a high tensile ductility, strain hardening, and small crack widths in the range of 20-80 $\mu \mathrm{m}$ (Li et al. 1997; Yang 2008; Yang et al. 2009). Cracks smaller than $50 \mu \mathrm{m}$ show complete healing and cracks up to $150 \mu \mathrm{m}$ show partial healing (Yang et al. 2009), but only in the presence of water. If no water is present, there will not be any form of autogenous healing (Snoeck et al. 2012b; Yang 2008; Yang et al. 2009). Recent studies aimed at a crack width of $30 \mu \mathrm{m}$ maximum to ensure a complete healing of the crack by means of autogenous healing (Snoeck and De Belie 2012; Snoeck et al. $2012 b)$. The crack hereby visually closed completely and a regain of approximately 50\% in mechanical properties was achieved (Snoeck et al. 2012b).

Without the presence of water, cracks in the cementitious material will not show autogenous healing. The self-healing capability of concrete can be improved by adding superabsorbent polymers (SAPs). These polymeric networks have the ability to absorb and retain a vast amount of liquid without dissolving, swelling to huge proportions due to osmosis. The use of SAPs to promote autogenous healing is dual. SAP particles swell due to water uptake during the mixing process and shrink during hardening of the concrete, leaving behind macropores (Yao et al. 2012). These macropores act as initial flaws and promote multiple cracking. Second, SAP particles are very useful for autogenous healing because they absorb water during wet periods and slowly release it during dry periods. Water is thus continuously available for the autogenous healing process and the composite can show a complete regain in mechanical properties, with healing of cracks up to $130 \mu \mathrm{m}$ (Kim and Schlangen 2010; Snoeck et al. 2012b) under wet-dry cycles. Also, as the SAPs swell, they will initially seal a crack from intruding fluids, thus increasing the durability (Lee et al. 2010a, b; Snoeck et al. 2012a, b). In this 


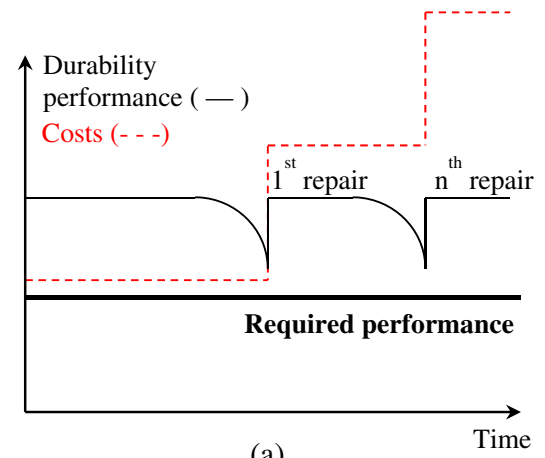

(a)

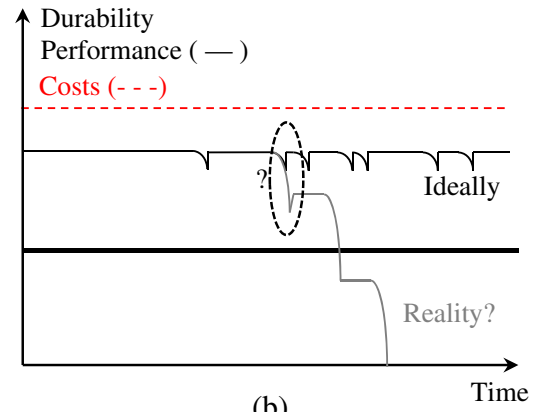

(b)

Fig. 1. (a) Durability performance and costs as a function of time for manual repair in a traditional structure; (b) for an (ideal) autogenously healing material (data from van Breugel 2007)

way, a smart cementitious material that is reliable and less independent from external conditions is acquired.

If this self-healing material is used in practice, several robustness criteria need to be met. These are a long shelf life, pervasiveness, economical advantage, stability, quality, reliability, versatility, and repeatability (Li and Herbert 2012; Yang 2008). In this paper, the focus lies on repeatability after the first healing action due to autogenous healing, which is related to quality and reliability.

If Fig. 1(a) is considered for a traditional structure, the durability performance of a construction is higher than the required performance. But, if there is excessive loading and/or cracking, this durability parameter may shift to lower values and degradation may occur. If one does not notice the failure and does not repair, the construction may decline (if the durability performance drops below the required performance line). The increases in durability performance are preventive and essential maintenance to rehabilitate the structure. The dashed curve shows the costs. The costs will increase stepwise in time due to maintenance monitoring and manual repair (van Breugel 2007).

If an ideal self-healing material would be used, the durability could be guaranteed [Fig. 1(b)] without human intervention. But, in the case of autogenous healing, the amount of available building blocks is consumed in time, thus limiting the possibility of renewed crack healing [indicated by means of a question mark in Fig. 1(b)]. So, the question arose whether this autogenous healing could be repeated. What will happen when autogenously healed specimens are again subjected to cracking? In this paper, the possibility of a repeatable autogenous healing is investigated by performing repeated four-point bending tests on self-healing materials.

\section{Materials and Methods}

\section{Materials}

The reference mortar mixtures contain CEM I $52.5 \mathrm{~N}$ (Holcim, Belgium), Class F fly ash (OBBC, Belgium), silica sand M34 ( $D_{50}=$ $170 \mu \mathrm{m}$; Sibelco, Belgium), water, polycarboxylate superplasticizer (Glenium 51, concentration 35\%; BASF, Germany), and PVA fibers
(2 v\%; $1.5 \times 10^{-6} \mathrm{~kg} / \mathrm{m}$ (15 dtex); $8 \mathrm{~mm}$ cutting length; $1.2 \mathrm{GPa}$ (12 cN/dtex) tenacity; Kuraray, Japan). The mixture composition is based on the one found by $\mathrm{Li}$ et al. (1997) and is given in Table 1. In other mixtures, a varying amount of SAP expressed as masspercentage $(\mathrm{m} \%)$ of cement weight was added on top of the reference mixture without SAPs. Two types of SAP from BASF were used: SAP A being a copolymer of acrylamide and sodium acrylate (particle size $100.0 \pm 21.5 \mu \mathrm{m}$ ), and SAP B, a cross-linked potassium salt polyacrylate $(476.6 \pm 52.9 \mu \mathrm{m})$ (Snoeck et al. 2014b). Both SAPs were produced through bulk polymerization and consisted of irregularly shaped particles.

To assess the sealing capacity of SAP, the swelling capacity was calculated from the volume increase between the vacuum-dried state and the saturated state of the SAP. A test fluid was added to vacuum-dried SAP particles and the whole was filtered after 1 day. The amount of filtered fluid was recorded. To ensure there was no influence of the filter paper, the latter was saturated with the fluid prior to filtration. The difference in mass of test fluid is the amount of test fluid absorbed by the SAP. By dividing this value by the initial mass of the SAP, the absorption capacity is determined. The measurements were performed with deionized water and filtered cement slurry (obtained by mixing 10 g CEM I $52.5 \mathrm{~N}$ in $100 \mathrm{~g}$ of deionized water) (Snoeck et al. 2014b). The absorption capacity is $305 \pm 4 \mathrm{~g}$ deionized water/g SAP A, $283 \pm 2 \mathrm{~g}$ deionized water/g SAP B, $61 \pm 1 \mathrm{~g}$ filtered cement slurry/g SAP A, and $58 \pm 2 \mathrm{~g}$ filtered cement slurry/g SAP B. SAP A particles are able to extract $25.6,83.1$, and $393.8 \%$ of their weight in moisture from the air in an environment with 60,90 , and $98 \%$ relative humidity (RH), respectively. SAP B particles are able to extract 28.1, 84.0, and $394.1 \%$, respectively. The latter was determined by using dynamic vapor sorption (DVS) in which the relative humidity can be changed in a controlled nitrogen environment while measuring the weight of the sample (Snoeck et al. 2014a).

\section{Mixing, Casting, and Storage Procedures}

First, the cement, fly ash, and possibly SAPs (depending on the mixture composition) were equally distributed with a mortar mixer.

Table 1. Mortar Composition of the Studied Mixtures

\begin{tabular}{|c|c|c|c|c|c|c|c|c|c|c|}
\hline $\begin{array}{l}\text { Sample } \\
\text { code }\end{array}$ & $\begin{array}{c}\mathrm{m} \% \mathrm{SAP}^{\mathrm{a}} \\
(\%)\end{array}$ & $\begin{array}{l}\text { SAP } \\
\text { type }\end{array}$ & $\begin{array}{l}\text { Cement } \\
\left(\mathrm{kg} / \mathrm{m}^{3}\right)\end{array}$ & $\begin{array}{l}\text { Fly ash } \\
\left(\mathrm{kg} / \mathrm{m}^{3}\right)\end{array}$ & $\begin{array}{c}\text { Sand } \\
\left(\mathrm{kg} / \mathrm{m}^{3}\right)\end{array}$ & $\begin{array}{c}\text { Water } \\
\left(\mathrm{kg} / \mathrm{m}^{3}\right)\end{array}$ & $\begin{array}{l}\text { Additional water } \\
\left(\mathrm{kg} / \mathrm{m}^{3}\right)\end{array}$ & $\begin{array}{c}\text { Superplasticizer } \\
\left(\mathrm{kg} / \mathrm{m}^{3}\right)\end{array}$ & $\begin{array}{l}\text { Fibers } \\
\left(\mathrm{kg} / \mathrm{m}^{3}\right)\end{array}$ & $\begin{array}{c}\mathrm{SAP} \\
\left(\mathrm{kg} / \mathrm{m}^{3}\right)\end{array}$ \\
\hline 0 & 0 & - & 608 & 608 & 426 & 365 & - & 12 & 26 & 0 \\
\hline $0.5 \mathrm{~A}$ & 0.5 & A & 554 & 554 & 388 & 333 & 84 & 11 & 26 & 2.77 \\
\hline $0.5 \mathrm{~B}$ & 0.5 & B & 590 & 590 & 413 & 354 & 26 & 11 & 26 & 2.95 \\
\hline 1B & 1 & B & 572 & 572 & 400 & 343 & 51 & 11 & 26 & 5.72 \\
\hline
\end{tabular}

${ }^{\mathrm{a}}$ Mass percent of SAP versus cement weight. 
Then, water and superplasticizer were added and mixed for $30 \mathrm{~s}$ at 140 revolutions per minute (rpm). The fine silica sand was added during the next $30 \mathrm{~s}$ at $140 \mathrm{rpm}$. To ensure a homogeneous dispersion of all components, the speed was increased for the following $30 \mathrm{~s}$ to $285 \mathrm{rpm}$. The edges of the bowl were scraped during $30 \mathrm{~s}$ and the mixture was then resting for a period of $60 \mathrm{~s}$. Subsequently, at a speed of $140 \mathrm{rpm}$, microfibers were slowly added during $30 \mathrm{~s}$. The final step was mixing for $60 \mathrm{~s}$ at $285 \mathrm{rpm}$.

A comparison of the flow value of mixtures with and without SAPs was used to reflect the absorption of mixing water by the SAPs in the mortar mixture (Schröfl et al. 2012). The mortar was hereby spread by jolting a plate 15 times and the flow diameter was then determined on two perpendicular axes [EN 12350-5 (European Committee for Standardization 2009)]. The amount of additional mixing water calculated based on the outcome of the previous test was increased several times in multiple mixtures with the same amount of SAPs until the flow value of both mixtures with and without SAPs was equal $(175 \mathrm{~mm})$. The determined amount of additional water is shown in Table 1.

Molds $\left(160 \times 40 \times 10 \mathrm{~mm}^{3}\right.$ samples $)$ were filled and the samples were compacted by jolting 60 times. The samples were demolded after $24 \mathrm{~h}$ and were stored at a relative humidity of $95 \pm 5 \%$ and a temperature of $20 \pm 2{ }^{\circ} \mathrm{C}$ until the age of 28 days. Series used within this study (Table 2) consisted of a minimum of three $160 \times 40 \times 10 \mathrm{~mm}^{3}$ samples with $2 \mathrm{v} \%$ of PVA microfibers.

\section{Four-Point Bending and Curing Conditions}

Cracks were created in the specimens by a four-point bending test at the age of 28 days. A servohydraulic testing system (Walter+Bai DB 250/15) ensured a displacement-controlled test $(0.0015 \mathrm{~mm} / \mathrm{s}$ to imitate a quasi-static load). The lower span was $140 \mathrm{~mm}$ and the upper loading span was $40 \mathrm{~mm}$ (Snoeck et al. 2014b). The strain at the bottom side of the specimen was limited to $1 \%$, theoretically calculated from the curvature and the vertical displacement during loading. This strain is lower than the maximum possible strain upon failure of such a strain-hardening specimen, so the service cracks could be studied before opening due to pullout of the fibers. After cracking, the samples were stored in three different conditions to allow crack healing:

1. At $20 \pm 2^{\circ} \mathrm{C}$ by applying wet-dry cycles (alternatively stored in water for $12 \mathrm{~h}$, and at a RH of $60 \%$ for $12 \mathrm{~h}$ );

2. In a room with a $\mathrm{RH}>90 \%$; and

3. In a room with a $\mathrm{RH}=60 \%$.

Table 2. Explanation of the Different Samples Codes

\begin{tabular}{llcc}
\hline Sample code & $\begin{array}{c}\mathrm{m} \% \mathrm{SAP}^{\mathrm{a}} \\
(\%)\end{array}$ & SAP type & Curing \\
\hline $0-60$ & 0 & - & $\mathrm{RH}=60 \%$ \\
$0-90$ & 0 & - & $\mathrm{RH}>90 \%$ \\
$0-$ wd & 0 & - & Wet-dry \\
$0.5 \mathrm{~A}-60$ & 0.5 & $\mathrm{~A}$ & $\mathrm{RH}=60 \%$ \\
$0.5 \mathrm{~A}-90$ & 0.5 & $\mathrm{~A}$ & $\mathrm{RH}>90 \%$ \\
$0.5 \mathrm{~A}-$ wd & 0.5 & $\mathrm{~A}$ & Wet-dry \\
$0.5 \mathrm{~B}-60$ & 0.5 & $\mathrm{~B}$ & $\mathrm{RH}=60 \%$ \\
$0.5 \mathrm{~B}-90$ & 0.5 & $\mathrm{~B}$ & $\mathrm{RH}>90 \%$ \\
$0.5 \mathrm{~B}-$ wd & 0.5 & $\mathrm{~B}$ & Wet-dry \\
1B-60 & 1 & $\mathrm{~B}$ & $\mathrm{RH}=60 \%$ \\
1B-90 & 1 & $\mathrm{~B}$ & $\mathrm{RH}>90 \%$ \\
1B-wd & 1 & $\mathrm{~B}$ & Wet-dry \\
\hline
\end{tabular}

${ }^{\mathrm{a}}$ Mass $\%$ of SAP versus cement weight.

\section{Regain in Mechanical Properties}

After a period of 28 days of healing, the specimens were reloaded in four-point bending [Fig. 2(a)] and the mechanical properties, obtained during the first and second loading cycle, were compared [Fig. 2(b)]. These properties are the first-cracking strength, the modulus of elasticity, the amount of multiple cracking, the regain in first-cracking strength, the regain in modulus of elasticity, and the residual amount of multiple cracking. The first-cracking strength was defined just before the first drop in stress due to an unstable extension in the matrix fiber tunnel. The modulus of elasticity is defined as the slope of the stress-strain curve before actual first cracking. The amount of multiple cracking was defined as the strain at the bottom of the specimen starting from the strain related to the first-cracking strength until the point of reloading or strain softening (where there is no longer strain hardening, but a decrease in strength in time due to failure of the fiber bridging action).

Again, the strain was limited to $1 \%$. After another 28 days of curing, the specimens were reloaded for a second time, until failure in the third loading cycle. From the additionally obtained stressstrain curves, the first-cracking strength and regain in first-cracking strength were again compared with the original and previous curve of first loading using Eq. (1)

$$
\text { Regain in } \sigma \text { at first or second reloading }=\frac{\sigma_{\text {first } / \text { second reloading }}}{\sigma_{\text {preloading }}}
$$

where $\sigma_{\text {preloading }}=$ first-cracking strength at preloading; $\sigma_{\text {firstreloading }}=$ first-cracking strength at reloading the specimen for the first time; and $\sigma_{\text {secondreloading }}=$ first-cracking strength at second reloading [Fig. 2(b)].

The regain in Young's modulus is calculated with the following Eq. (2):

$$
\begin{aligned}
& \text { Regain in } E \text { at first or second reloading } \\
& =\frac{E_{\text {first } / \text { second reloading }}-E_{\text {first/second residual }}}{E_{\text {preloading }}-E_{\text {first/second residual }}}
\end{aligned}
$$

where $E_{\text {preloading }}=$ modulus of elasticity at preloading; $E_{\text {firstreloading }}=$ modulus of elasticity at reloading the specimen for the first time; $E_{\text {secondreloading }}=$ modulu of elasticity at second reloading; $E_{\text {firstresidual }}=$ residual modulus at preloading; and $E_{\text {secondresidual }}=$ residual modulus at first reloading [Fig. 2(b)]. The residual strength was calculated between the point at start of unloading and the point of total unloading.

The residual amount of multiple cracking was determined until the point of strain softening, assuming an already imposed strain of $2 \%$ from the two previous loading parts.

Fig. 2(b) represents the stress-strain curves of a specimen healed in wet-dry cycles, and three loading cycles are visible. The first loading part is the preloading (strain from 0 until 1\%), the second part is the first reloading (an additional strain of 1\%), and the third part is the second reloading (until failure).

After preloading and before healing, initial microscopic observations were performed by means of a stereo microscope (Leica S8 APO with DFC 295 camera). During the healing periods, additional microscopic observations were performed at regular time intervals and the crack width was measured and studied in time. The visual closure hereby served as a qualitative measurement for the autogenous healing capacity.

Some specimens were loaded until failure at the first and second cycle to study the effect of autogenous healing on larger cracks. Because the regain in mechanical properties of the failed specimens 

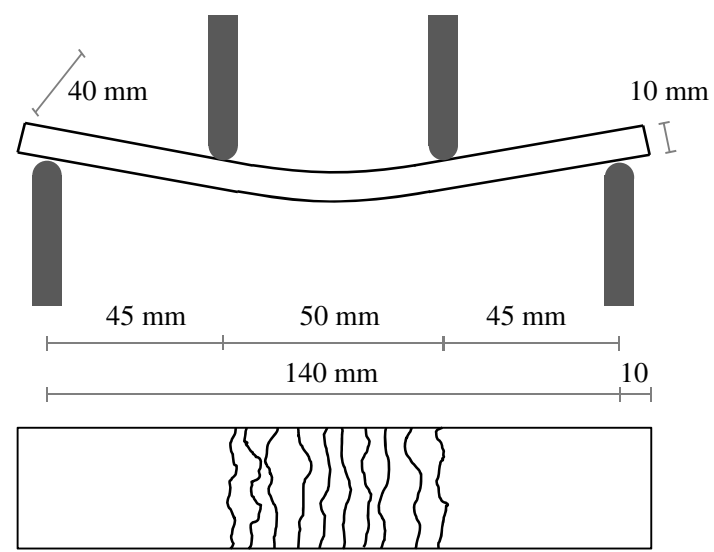

(a)

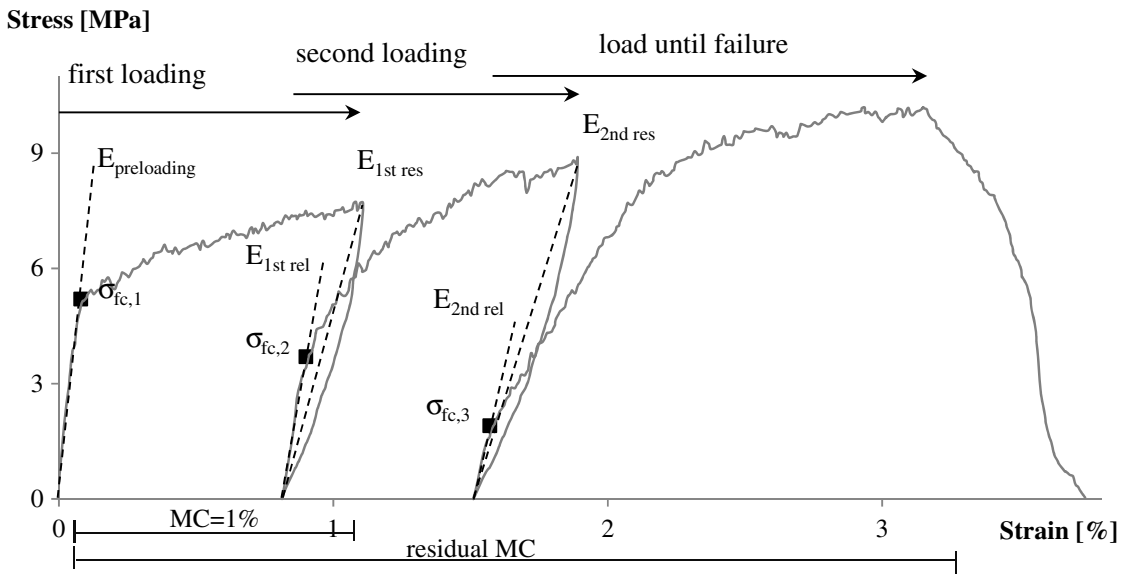

(b)

Fig. 2. (a) Test setup of four-point bending with typical amount of multiple cracking; (b) typical stress-strain curve with the different cracking and healing stages, together with the indication of first-cracking strengths $\sigma_{f c}$ and the slopes of the curve at every stage

is low, these specimens were only used to perform microscopic analysis and to study the limit of autogenous healing.

\section{Thin Section Analysis}

Thin sections $(40 \mathrm{~mm} \times 10 \mathrm{~mm} \times 25 \mu \mathrm{m})$ were prepared from studied four-point bending specimens after storage in healing conditions (at a total age of 56 days) (Fig. 3). First, the specimens were cut to receive $40 \times 10 \mathrm{~mm}$ faces, which were then glued on a glass slide with a thickness of $2.9 \mathrm{~mm}$. The combined sample was cut and polished until a height of the specimen and glass of $10.1 \mathrm{~mm}$ was reached. Next, the specimens were impregnated under vacuum with a fluorescent epoxy. The excess epoxy was polished away and an object glass was glued on the smooth surface. Finally, the glass slides were cut off and the remaining part was polished until a thin section with $25-\mu \mathrm{m}$ thickness was achieved. The epoxy ensured stable handling of the whole specimen and the healing products were untouched. A cover glass was glued on top to protect the thin section. The thin sections were analysed with a Leica DM LP microscope with a DFC 295 camera. Normal light, polarized light, and fluorescent light were used to visualize the formed crystals in a crack and the change in microstructure around the crack faces.

\section{Statistical Analysis}

A statistical analysis was performed by using the program SPSS to compare obtained results. Multiple averages were compared using
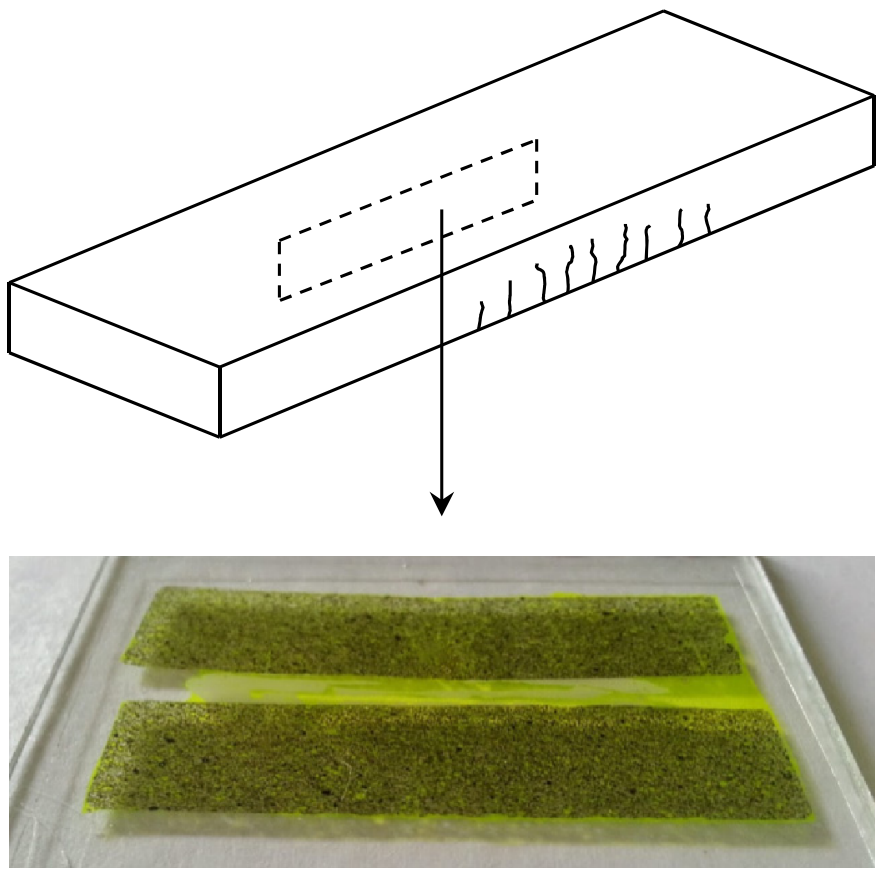

Fig. 3. Schematic overview of the location of the thin section in a specimen used for four-point bending 
an ANOVA test with a significance level of 5\%. The homogeneity of the variances was controlled with a Levene's test. The post hoc test for data with homogenous variances was a Student-NewmanKeuls test and if no homogenous variances were obtained, a Dunnett's T3 test was used.

\section{Results and Discussion}

Due to the addition of microfibers, multiple cracking was observed, giving all samples a ductile strain-hardening behavior (Fig. 2). The crack width is hereby a very important parameter. If large cracks are formed, the building blocks for self-healing will be consumed after some time and the autogenous healing will no longer be optimal. In this research, the crack widths were limited to 30-50 $\mu \mathrm{m}$, as was also the case in Yang (2008). The mean crack widths were $24.0 \pm 12.2 \mu \mathrm{m}$ in case of specimens without SAPs. Due to the addition of SAP particles, this multiple cracking behavior was enhanced as the total maximum strain was increased. The macropores formed by the SAPs act as crack initiators, increasing the ductile behavior. Also, the crack width was approximately the same $(23.7 \pm 13.4 \mu \mathrm{m}$ for specimens with SAPs). Due to partial reopening of the cracks at first reloading and the formation of

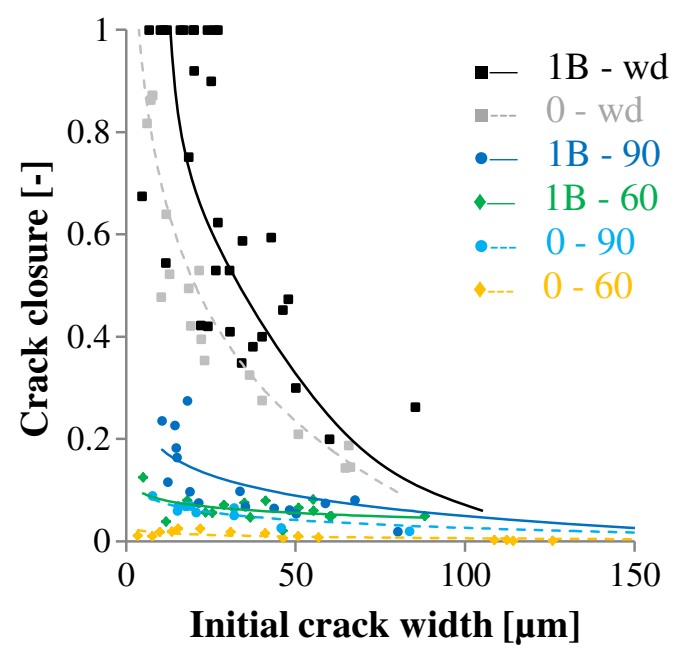

(a)

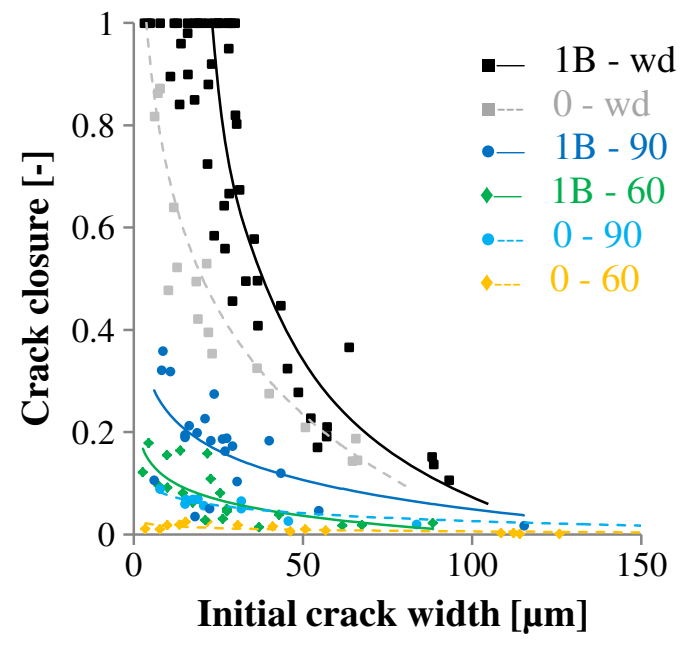

(c) new cracks, the crack width increased slightly (to $25.7 \pm 15.9 \mu \mathrm{m}$ for specimens without SAPs and $25.5 \pm 15.6 \mu \mathrm{m}$ for specimens with SAPs).

By examining the crack width before and after healing, the percentage of crack closure could be quantified. Fig. 4(a) shows the visual crack closure in function of the initial crack width after the first healing cycle. Results show that cracks up to $30 \mu \mathrm{m}$ are able to heal completely at the crack mouth and up to $150 \mu \mathrm{m}$ heal partly when specimens are subjected to wet-dry cycles. Yang (2008) and Li et al. (1997) had similar results, but their limit of total crack healing was $50 \mu \mathrm{m}$ instead of $30 \mu \mathrm{m}$. They also showed that, when stored in ambient air with a certain relative humidity (without any liquid water available), samples cannot heal. In this study, samples without SAPs stored in laboratory conditions did not show healing. The cracks of specimens stored in wet-dry cycles were filled with a whitish healing product. Postanalysis by means of thermogravimetric analysis showed that this product is a mix of calcium carbonate crystals and hydration products (Snoeck et al. 2014b).

Specimens used to study the self-healing capacity were limited to $1 \%$ strain. As mentioned previously, the crack widths were thus limited. The larger crack widths found in Fig. 4(a) originate from specimens that were loaded until failure. Due to the higher loading

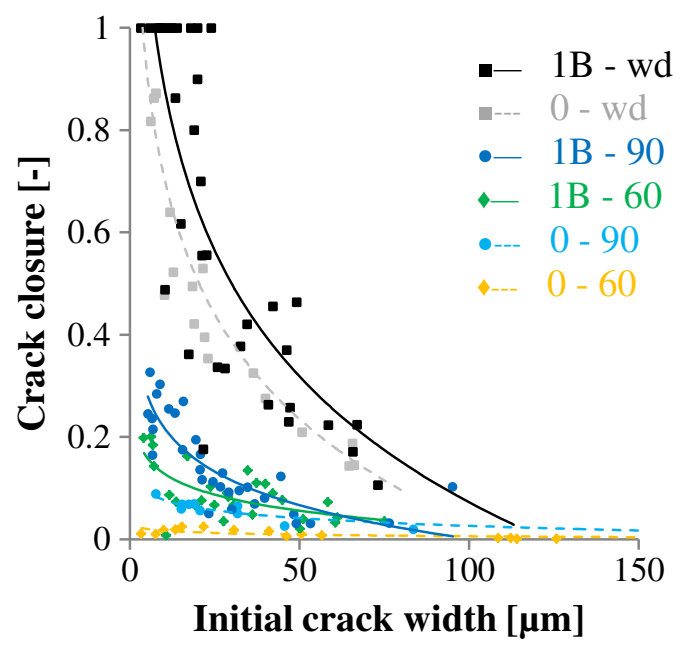

(b)

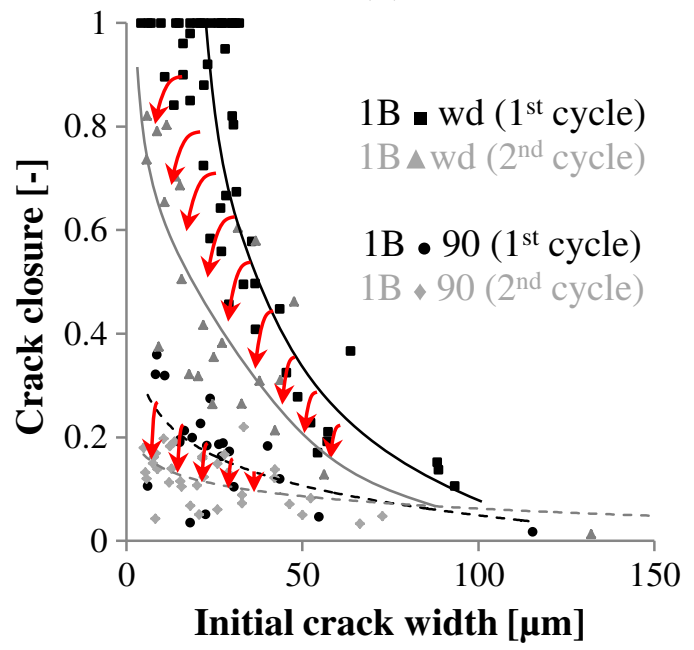

(d)

Fig. 4. (a) Crack closure [-] after the first healing stage as a function of initial crack width of $0.5 \mathrm{~A}$; (b) $0.5 \mathrm{~B}$; (c) $1 \mathrm{~B}$; (d) a comparison between the first and second healing stage of $1 \mathrm{~B}$ 
strain, the crack widths were larger in those specimens. These crack widths were studied on their healing capacity as well to obtain results for partial healing and the boundary criterion for ideal autogenous healing in the studied strain-hardening cementitious materials. That criterion was found to be $30 \mu \mathrm{m}$.

It is clear that specimens healed under wet-dry cycles exhibit the best healing because a fair amount of water is available for autogenous healing [Fig. 4(a)]. If superabsorbent polymers are added as well, the amount of healing with wet/dry cycles is slightly higher [Figs. 4(a-c)]. This is due to the fact that SAPs are able to seal a crack from intruding fluids, reducing the flow when put under water and thus establishing better circumstances for autogenous healing. The better circumstances are due to the lower fluid flow and thus less washing out of the healing products, as also found by Edvardsen (1999). Second, water is also available during the dry periods of the wet-dry cycle, thus increasing the possibility of autogenous crack healing. At a relative humidity of more than $90 \%$, the healing is far less compared with the healing condition with wet-dry cycles because no water is present. However, specimens with superabsorbent polymers show partial healing. Because SAPs are able to extract moisture from the environment, they will swell to a small extent, and then provide the necessary water for further hydration of unhydrated binder particles in the crack. At a relative humidity of $60 \%$, only the mixtures with SAPs show partial healing. The visual crack closure is important because a completely closed crack will be beneficial as harmful substances may no longer enter a crack in the future.

The mixtures 0.5A [Fig. 4(a)] and 0.5B [Fig. 4(b)] show the same visual closure at the crack mouth. Their differences are not significant. A doubling of the amount of SAPs [0.5B, Fig. 4(b), and 1B, Fig. 4(c)] increases the amount of available water held by the SAPs to stimulate autogenous healing, leading to better properties and visual closure in 1B mixtures. Previous research showed that $1 \mathrm{~B}$ provides the best results considering self-sealing (Snoeck et al. 2012b).

After the first healing period, most of the building blocks for self-healing, i.e., unhydrated cement particles and $\mathrm{Ca}^{2+}$ ions, are consumed, reducing the possibility for autogenous healing. Specimens with SAPs in the second wet-dry cycle, for example, show an inferior visual closure of the crack compared with the same specimens in the first healing cycle [Fig. 4(d)]. This already points out that the regain of mechanical properties upon the second healing will be lower compared with the first healing.

The strength of the new material was investigated by analyzing the results from the loading experiments. The first-cracking strength of all studied mixtures is shown in Fig. 5(a). The values found correspond to literature (Kim and Schlangen 2010). The first-cracking strength for the mixtures without SAPs is higher than for the mixtures with SAPA. Due to the macropores in the mixtures with SAP particles, the active cross section is reduced, resulting in a lower first-cracking strength. The macropores formed after emptying the water-filled SAP inclusions, however, may also promote the multiple cracking behavior because they serve as crack initiators. Their effect is thus dual: they will assist in multiple crack formation, but at the same time decrease the strength. The strength is not reduced significantly when using the larger SAP B particle. Compared with SAP A, SAP B has less influence on the strength because a lower amount of macropores is distributed throughout the cementitious matrix. This results in macropores not decreasing the strength too much even though the macropores are substantially bigger in size. However, there is a difference in swelling capacity and there is a difference in specific surface, explaining the influence on the strength. The combined effect by the SAPs due to the formation of macropores and internal curing can be found in Snoeck et al. (2014c).

Samples with SAPs show a higher regain in first-cracking strength than the SAP-free samples under all studied healing conditions [Fig. 5(b)]. The regained first-cracking strength for the samples healed in wet-dry cycles is higher than for those healed in an environment with a $\mathrm{RH}>90 \%$, which, in turn, is higher than for those healed in an environment with a $\mathrm{RH}=60 \%$. Healing in wet-dry cycles provides the necessary water for the hydration of cement particles, the puzzolanic reaction of fly ash, and for calcium carbonate crystallization. Increasing the amount of SAP from 0.5 to $1 \mathrm{~m} \%$ also increases the regain in strength because more water is available to trigger the three previously mentioned autogenous healing mechanisms.

The value of $46 \%$ regain in first-cracking strength in mixtures without SAPs after wet-dry cycles [Fig. 5(b)] is comparable to the value of approximately $42 \%$ found in similar mixtures by



(a)



(b)

Fig. 5. (a) Mean first-cracking strength $\sigma_{f c}$ at 28 days with standard deviation $(n=3)$; (b) regain in first-cracking strength after the first and second healing period for all studied mixtures 


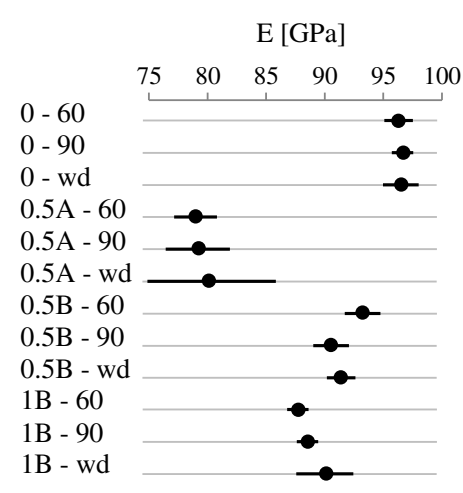

(a)



(b)

Fig. 6. (a) Mean modulus of elasticity $E$ at 28 days with standard deviation ( $n=3$ ); (b) regain in modulus of elasticity after the first and second healing period for all studied mixtures

Yang (2008). The values found in literature (Yang 2008) for storage in a relative humidity of more than $90 \%$ (23\% regain in firstcracking strength) and in a relative humidity of $60 \%$ (13\% regain in first-cracking strength) correspond very well to the values found for specimens without SAPs in this research: 20 and $7 \%$, respectively.

SAP particles not only tend to increase the healing capacity during the first healing stage (from 46 to $75 \%$ in wet-dry cycles), but also during the second healing stage (Fig. 5). The regain is still $66 \%$ at second reloading. Without the superabsorbent polymers, this value was only $28 \%$ (wet-dry cycles). A possible explanation is the storage of a calcium-rich fluid (i.e., the pore solution) in the swollen superabsorbent polymers. This provides the possibility of the formation of the $\mathrm{CaCO}_{3}$ crystals in the crack. If superabsorbent polymers are not present, this fluid is expected to be washed out from a crack upon drying. The crystal formation was also visible at the face of the specimens containing SAPs. Domelike structures were formed, proving the theory of retained pore solution, used during the crystallization process. The dome structures were also found in Snoeck et al. (2014b). By providing this retained pore solution to the matrix, the autogenous healing is promoted, both in the first and in the second healing stage. This autogenous healing was mostly present at the surface, but also in the interior of a crack.

The same conclusions can be drawn if the modulus of elasticity of the different mixtures is compared (Fig. 6). As was the case for the regain in first-cracking strength, the regain in modulus of elasticity for the samples healed in wet-dry cycles is higher than for those healed in an environment with a $\mathrm{RH}>90 \%$, which, in turn, is again higher than for those healed in a $\mathrm{RH}=60 \%$. When using SAP particles, the overall healing is increased (from 19 to $70 \%$ in wet-dry cycles). Upon second reloading, the crystals are assumed to be less strong and the regain is also less. The regain in mean modulus of elasticity in 1B mixtures is still higher than for the reference samples without SAPs upon first reloading. The regain in modulus of elasticity can also be due a stronger matrix and higher bond with the microfibers (Li et al. 2002). The study of the modulus of elasticity was only used as a verification of the results found by comparing the regain in first-cracking strength.

The amount of multiple cracking is visualized in Fig. 7(a). This is the strain of specimens completely loaded until failure, without imposing several loading cycles. Specimens without SAPs show a strain of $2 \%$, which is a normal value for these kind of strainhardening materials (Li et al. 1997). Due to the use of SAPs, the amount of multiple cracking increases. This is due to the presence of crack initiators, facilitating the formation of additional cracks before failure of one of the already-bridged cracks. A higher amount of SAPs leads to a higher amount of multiple cracking. This statement, however, is only valid because the strength is not significantly impaired. Due to healing, the residual amount of multiple cracking is increased. This is only significantly the case when stored in wet-dry cycles, especially considering the $1 \mathrm{~B}$ mixtures. Again the same trends are visible. The storage in wet-dry



(a)

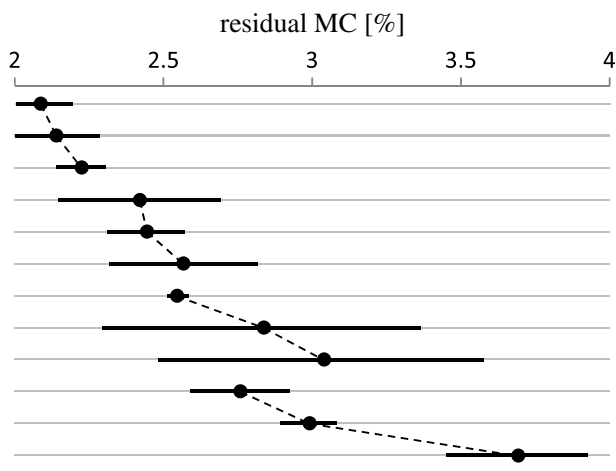

(b)

Fig. 7. (a) Mean amount of multiple cracking at 28 days with standard deviation $(n=3)$; (b) residual amount of multiple cracking after imposing two times $1 \%$ strain for all studied mixtures 


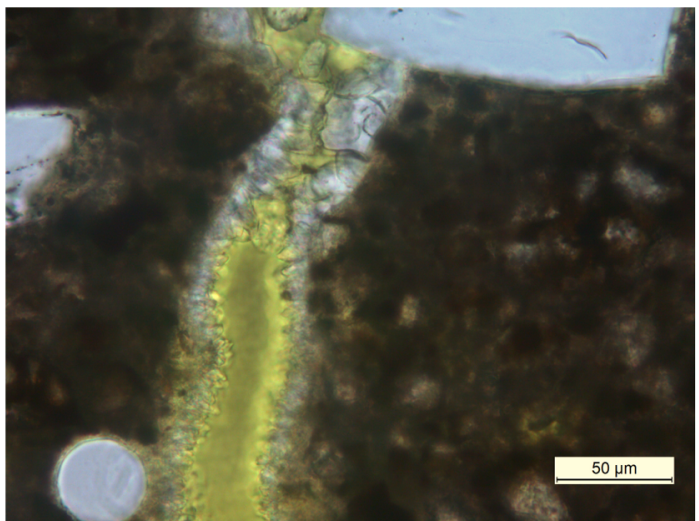

(a)

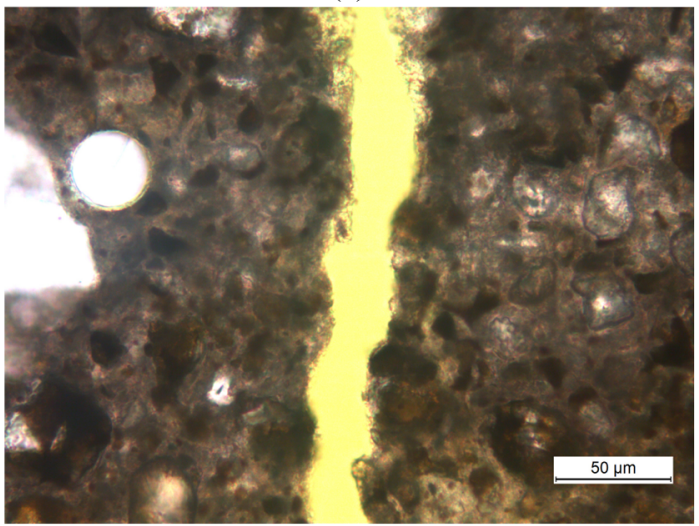

(c)



(e)

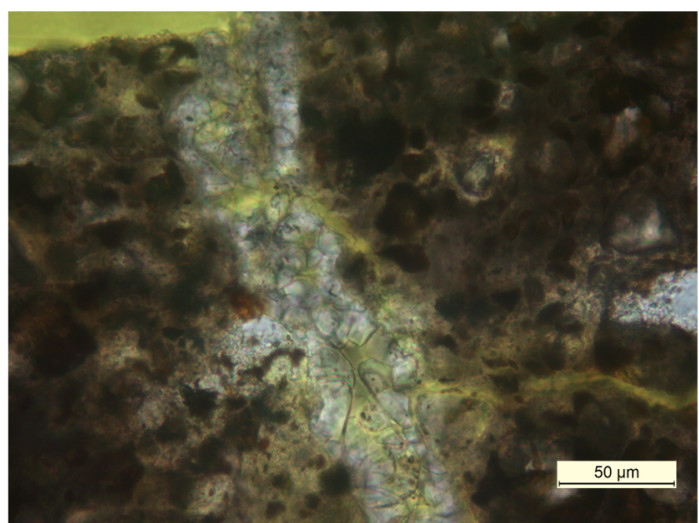

(b)

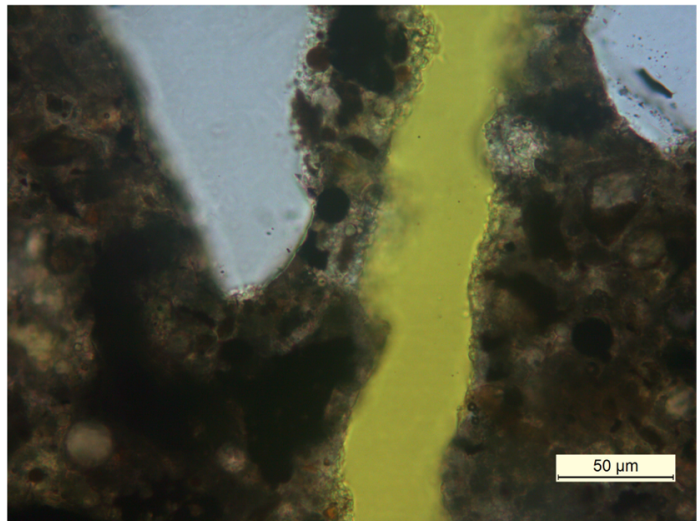

(d)

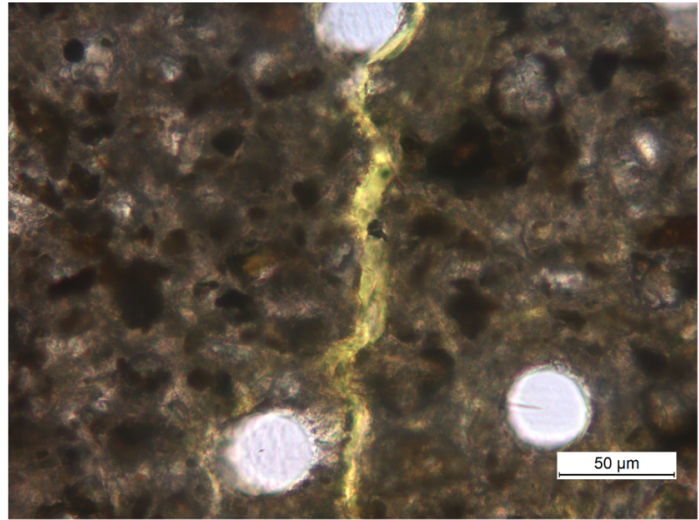

(f)

Fig. 8. Thin sections of a crack (a, c, and e) in a reference cementitious material and (b, d, and f) in a cementitious material with superabsorbent polymers mixed in under cross-polarized light, showing crystal formation at the crack faces when stored in (a and b) wet-dry cycles, (c and d) partial healing due SAPs when stored in a room at $>90 \% \mathrm{RH},(\mathrm{e}-\mathrm{f})$ and $\mathrm{RH}=60 \%$; all micrographs were taken at the crack mouth; the scale bar shows a distance of $50 \mu \mathrm{m}$

cycles leads to better healing properties compared with $>90 \% \mathrm{RH}$ and $=60 \%$ RH. SAPs again seem to stimulate autogenous healing, which in turn leads to enhanced mechanical properties.

Fig. 8 shows micrographs of thin sections of the interior of a crack of a specimen with and without SAP particles at the crack mouth. Abundant crystal formation can be seen in specimens stored in wet-dry cycles [Figs. 8(a and b)]. Crystals are mainly formed where hydration products are present at the crack face. At the lighter parts (i.e., the sand particles) at the crack faces, there is less crystal formation. Because $\mathrm{CaCO}_{3}$ primarily needs $\mathrm{Ca}^{2+}$ ions, those cannot be provided by the sand particles, explaining the lower amount of crystals found at the sand particle edges. Also, a small difference in color can be seen in different crystal clusters. The darker crystal formation is likely to be a mix of $\mathrm{CaCO}_{3}$ and $\mathrm{Ca}(\mathrm{OH})_{2}$, formed by further hydration. The pure white crystals are likely to be pure $\mathrm{CaCO}_{3}$. At the crack mouth, the crystals are able to bridge the crack, leading to the regain in mechanical properties. The crystals are formed from 400 until more than $1,000 \mu \mathrm{m}$ inside the crack (Fig. 9). In the interior of a crack, the amount of crystals is less and only at some distinct places the crystals bridge a crack, mostly in the vicinity of a fiber (because they act as a nucleation site for the calcium carbonate crystals). Because the crack is sealed at the surface from intruding water, the crystallization comes to a hold in the interior of the crack. Also, the closer to the crack tip, the further the hydration compared with calcium carbonate crystallization is found because the $\mathrm{CO}_{2}$ will 




Fig. 9. Thin section of the interior of a crack filled with healing products; the scale bar is $100 \mu \mathrm{m}$

preferably be used at the surface where it dissolves in the water layer during the wet-dry cycles. Fan and Li (2015) showed that the region close to the surface had a high amount of crystalline products $\left(\mathrm{CaCO}_{3}\right)$, as studied by means of X-ray computed microtomography $(\mu \mathrm{CT})$. At greater depths, there was a lower amount of healing products (especially further hydration and puzzolanic reactions). In this research, it is also mostly $\mathrm{CaCO}_{3}$ that is formed (crack mouth), but also a small part of further hydration (interior of crack and crack tip). Both mechanisms combined lead to up to $75 \%$ recovery of strength found in Fig. 5.

Jonkers (2011) showed in bacterial self-healing concrete that precipitation mainly occurred near the crack rim leaving major parts of the crack unhealed. His research was conducted on specimens with a $150-\mu \mathrm{m}$ crack width, substantially higher than the $30-50 \mu \mathrm{m}$ crack width region studied in this paper. He explained the precipitation at the crack rim due to the relatively high solubility of calcium hydroxide. He hypotheses that calcium hydroxide

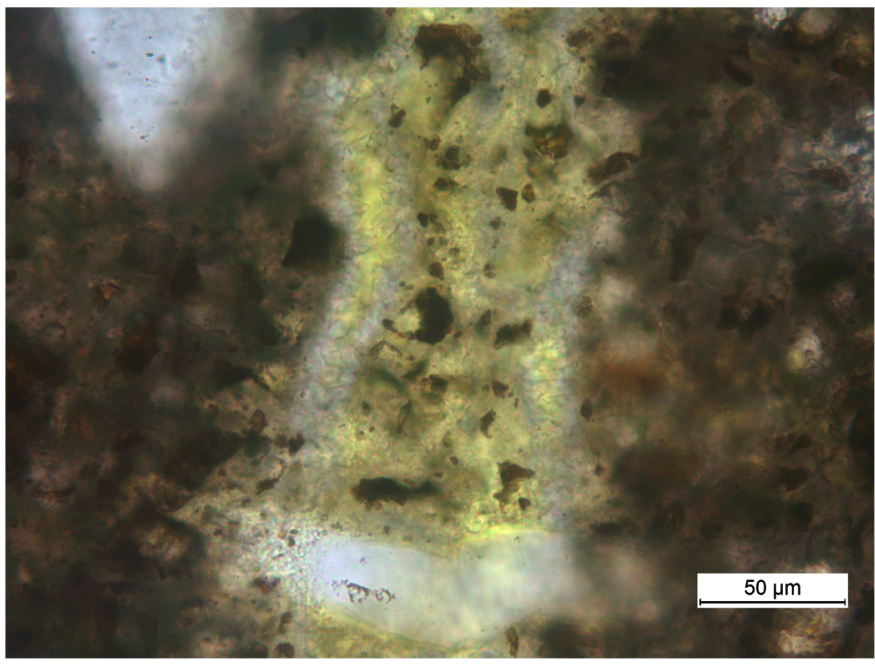

Fig. 10. Thin section of the interior of a crack filled with healing products after second autogenous healing; the scale bar is $50 \mu \mathrm{m}$

first uses the carbon dioxide from intruding water in the crack, and afterwards the remaining calcium hydroxide would dissolve and diffuse out of the crack into the bulk water. Here it will react with carbon dioxide present near the crack rim resulting in the precipitation of larger quantities of calcium carbonate.

The healing mechanism of $\mathrm{CaCO}_{3}$ crystals shows teethlike structures in the interior of a crack expanding towards each other and eventually making a solid bridge of a crack [Fig. 8(a)]. The amount of crystals is higher in specimens containing SAPs [Fig. 8(b)] compared with specimens without SAPs [Fig. 8(a)]. This is possibly due to the slow release of water to the cementitious matrix during dry periods by the swollen SAP particles near the crack face. In a storage condition of $>90 \% \mathrm{RH}$ and $=60 \% \mathrm{RH}$, almost no healing is found in specimens without SAPs [Figs. 8(c and e)]. Because no water is present to form autogenous healing products, no precipitates can be found. When investigating thin sections of specimens containing SAPs, partial crystal formation is found at the crack faces [Fig. 8(d)] and further hydration may occur [Fig. 8(f)] due to the release of extracted moisture by the SAP particles. This further hydration is beneficial in small cracks and at the crack tips, where a small amount of healing products is able to bridge a crack.

$\mathrm{Ca}^{2+}$ ions are consumed at the crack faces after the first healing period. This is connected to the results of the visual crack closure and the regain in mechanical properties. The visual crack closure is approximately $20 \%$ lower when the specimens are reloaded for a second time. An example of healing at second reloading is shown in Fig. 10. During the first reloading, only a limited number of new cracks are formed. The previous healed cracks thus mostly reopen and there is a limited possibility for a renewed autogenous healing of the crack. In the second healing stage, $\mathrm{Ca}^{2+}$ ions present in the interior of the matrix need to diffuse toward the crack face. So, the crystallization becomes diffusion-controlled instead of surfacecontrolled. This limits the speed of possible crystallization and thus autogenous healing and regain in mechanical properties.

During the formation of calcium carbonate crystals, an amount of $\mathrm{Ca}^{2+}$ needs to leach out from the cementitious matrix. The matrix in the vicinity of a crack may thus look brighter in comparison with the plain matrix (Fig. 11, clearly marked with the boundaries). In the interior of the crack, crystals are clearly formed. Thermogravimetric analysis (TGA) on material found in a crack showed that this was mainly $\mathrm{CaCO}_{3}$ with partial $\mathrm{Ca}(\mathrm{OH})_{2}$ 


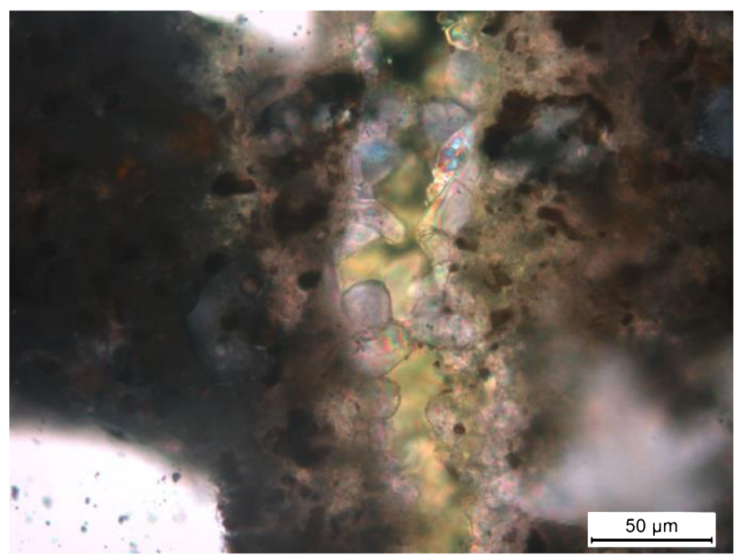

(a)

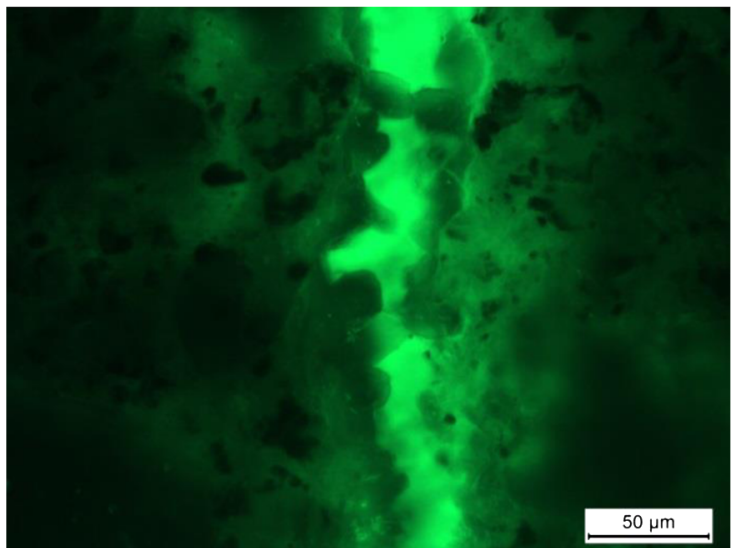

(c)

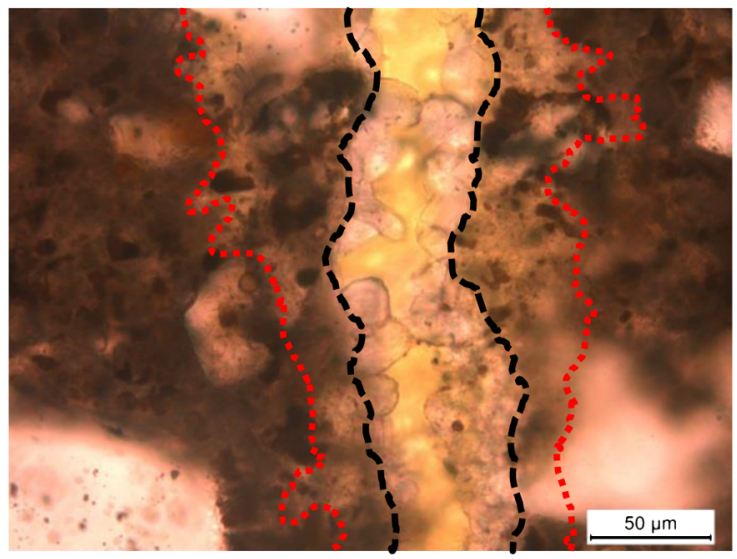

(b)

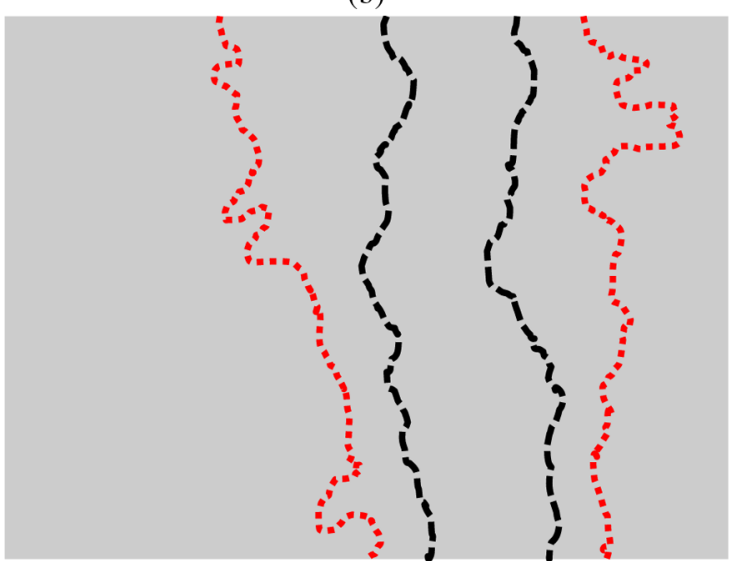

(d)

Fig. 11. Thin section of a crack in a cementitious material under (a) cross-polarized light, (b) normal light, and (c) fluorescent light; (b and d) the crack boundary is shown with a dashed line and the boundary of the region where $\mathrm{Ca}^{2+}$ has leached out with a dotted line; the scale bars are $50 \mu \mathrm{m}$

from further hydration (Snoeck et al. 2014b). When this healed crack is opened again, the $\mathrm{Ca}^{2+}$ will need to travel from a further distance compared with the first healing cycle and the material will be less able to regain its properties as less crystals are able to be formed. But, if the surface is sealed fast, the crystallization in the interior of a cracked specimen can still occur if the ions are not fully consumed. This led to the regain in mechanical properties at the second healing stage.

\section{Conclusions}

SAP particles promote self-healing by providing water on crack formation and this results in more visual crack closure and more regain in mechanical properties such as the first-cracking strength, the modulus of elasticity, and the amount of multiple cracking. The main mechanisms of autogenous healing are further hydration of unhydrated particles and the precipitation of $\mathrm{CaCO}_{3}$ on the crack faces. To a certain degree the autogenous healing capability of cementitious materials is maintained during subsequent loading cycles. Cracks heal and close during a second healing cycle and there is a regain in first-cracking strength of specimens stored in wet-dry cycles. Even in an environment with a $\mathrm{RH}>90 \%$, there is a nonnegligible healing capacity noticeable. Even though the active cross section is reduced due to the macropores resulting in a smaller first-cracking strength, this effect is not significant when using larger SAP particles. The smart material with SAP B is thus an excellent material to use in future building applications.
In wet-dry cycles, the plain material without superabsorbent polymers is able to regain $46 \%$ of its first-cracking strength after a first healing cycle. After the second healing cycle, this regain is $28 \%$. When superabsorbent polymers are used, the regain is 75 and $66 \%$, respectively. This increase is possibly due to the retained pore fluid and the reduced permeation through the crack. This causes the ideal conditions for promoted autogenous healing in the form of further hydration and calcium carbonate crystallization.

Analysis of thin sections showed that crystals are mainly formed near the crack mouth and are likely to be calcium carbonate. The $\mathrm{CaCO}_{3}$ crystallization at the first healing stage is mostly surfacecontrolled and the one at second healing is mostly diffusion-controlled. This is due to the consummation of $\mathrm{Ca}^{2+}$ ions due to autogenous healing itself during the first healing cycles. As the ions are used near the crack faces, additional $\mathrm{Ca}^{2+}$ ions will need to diffuse further through the matrix before being used in the crystallization process.

Generally, the overall healing and closure of a crack may lead to less ingress of potentially harmful substances, thus possibly increasing the durability and service life of civil structures. This feature is enhanced due to the swelling action of the superabsorbent polymers in a crack and the subsequent better crystallization in a crack.

\section{Acknowledgments}

As a research assistant of the Research Foundation-Flanders (FWO-Vlaanderen), D. Snoeck wants to thank the foundation for the financial support. The authors want to thank all companies for providing the needed materials and S. De Buck for preparing the 
thin cross sections. This work was partly carried out in the framework of the M.Sc. dissertation of S. Debaecke.

\section{References}

European Committee for Standardization. (2009). "Testing fresh concrete -Part 5: Flow table test, 8.

Edvardsen, C. (1999). "Water permeability and autogenous healing of cracks in concrete." ACI Mater. J., 96(4), 448-454.

Fan, S., and Li, M. (2015). "X-ray computed microtomography of threedimensional microcracks and self-healing in engineered cementitious composites." Smart Mater. Struct., 24(1), 015021.

Granger, S., Loukili, A., Pijaudier-Cabot, G., and Chanvillard, G. (2007). "Experimental characterization of the self-healing of cracks in an ultra high performance cementitious material: Mechanical tests and acoustic emission analysis." Cem. Concr. Res., 37(4), 519-527.

Homma, D., Mihashi, H., and Nishiwaki, T. (2009). "Self-healing capability of fibre reinforced cementitious composites." J. Adv. Concr. Technol., 7(2), 217-228.

Jonkers, H. M. (2011). "Bacteria-based self-healing concrete." Heron, $56(1 / 2), 1-12$.

Kim, J. S., and Schlangen, E. (2010). "Super absorbent polymers to simulate self healing in ECC." 2nd Int. Symp. on Service Life Design for Infrastructures, K. van Breugel, G. Ye, and Y. Yuan, eds., RILEM Publications SARL, Delft, the Netherlands, 849-858.

Lee, H. X. D., Wong, H. S., and Buenfeld, N. R. (2010a). "Potential of superabsorbent polymer for self-sealing cracks in concrete." Adv. Appl. Ceram., 109(5), 296-302.

Lee, H. X. D., Wong, H. S., and Buenfeld, N. R. (2010b). "Self-sealing cement-based materials using superabsorbent polymers." Proc., Int. RILEM Conf. on Use of Superabsorbent Polymers and Other New Additives in Concrete, RILEM, Paris, 171-178.

Li, V. C., and Herbert, E. (2012). "Robust self-healing concrete for sustaibable infrastructure." J. Adv. Concr. Technol., 10(6), 207-218.

Li, V. C., Wang, S., and Wu, C. (1997). "Tensile strain-hardening behavior of polyvinyl alcohol engineered cementitious composites (PVA-ECC)." ACI Mater. J., 98(6), 483-492.

Li, V. C., Wu, C., Wang, S., Ogawa, A., and Saito, T. (2002). "Interface tailoring for strain-hardening polyvinyl alcohol-engineered cementitious composites (PVA-ECC)." ACI Mater. J., 99(5), 463-472.

Schröfl, C., Mechtcherine, V., and Gorges, M. (2012). "Relation between the molecular structure and the efficiency of superabsorbent polymers
(SAP) as concrete admixture to mitigate autogenous shrinkage." Cem. Concr. Res., 42(6), 865-873.

Snoeck, D., et al. (2014a). "The influence of different drying techniques on the water sorption properties of cement-based materials." Cem. Concr. Res., 64, 54-62.

Snoeck, D., and De Belie, N. (2012). "Mechanical and self-healing properties of cementitious composites reinforced with flax and cottonised flax, and compared with polyvinyl alcohol fibres." Biosyst. Eng., 111(4), 325-335.

Snoeck, D., Dubruel, P., and De Belie, N. (2012a). "Superabsorbent polymers to prevent water movement in cementitious materials." Int. J. $3 R$ 's, 3(3), 432-440.

Snoeck, D., Schaubroeck, D., Dubruel, P., and De Belie, N. (2014c). "Effect of high amounts of superabsorbent polymers and additional water on the workability, microstructure and strength of mortars with a water-to-cement ratio of 0.50." Constr. Build. Mater., 72, 148-157.

Snoeck, D., Steuperaert, S., Van Tittelboom, K., Dubruel, P., and De Belie, N. (2012b). "Visualization of water penetration in cementitious materials with superabsorbent polymers by means of neutron radiography." Cem. Concr. Res., 42(8), 1113-1121.

Snoeck, D., Van Tittelboom, K., Steuperaert, S., Dubruel, P., and De Belie, N. (2014b). "Self-healing cementitious materials by the combination of microfibres and superabsorbent polymers." J. Intell. Mater. Syst. Struct., 25(1), 13-24.

SPSS [Computer software]. New York, IBM.

ter Heide, N. (2005). "Crack healing in hydrating concrete." Dissertation, Delft Univ. of Technology, Delft, the Netherlands.

van Breugel, K. (2007). "Is there a market for self-healing cement-based materials?" Proc., 1st Int. Conf. on Self-Healing Materials, RILEM, Paris, 1-9.

Van Tittelboom, K., Gruyaert, E., Rahier, H., and De Belie, N. (2012). "Influence of mix composition on the extent of autogenous crack healing by continued hydration or calcium carbonate formation." Constr. Build. Mater., 37, 349-359.

Yang, E.-H. (2008). "Designing added functions in engineered cementitious composites." Dissertation, Univ. of Michigan, Ann Arbor, MI.

Yang, Y., Lepech, M. D., Yang, E.-H., and Li, V. C. (2009). "Autogenous healing of engineered cementitious composites under wet-dry cycles." Cem. Concr. Res., 39(5), 382-390.

Yao, Y., Zhu, Y., and Yang, Y. (2012). "Incorporation of SAP particles as controlling pre-existing flaws to improve the performance of ECC." Constr. Build. Mater., 28(1), 139-145. 